\title{
ABORDAGENS BIOSSOCIAIS NA SOCIOLOGIA Biossociologia ou sociologia evolucionista?
}

\author{
André Luís Ribeiro Lacerda
}

Em 2009 comemora-se o bicentenário do nascimento de Charles Darwin. Nos últimos duzentos anos, podemos dizer que as idéias de Darwin produziram duas revoluções. A primeira ocorreu em 1859, em torno da publicação de $A$ origem das espécies. Contrariando o que era aceito na época, Darwin sustentou duas idéias: a de que as espécies não haviam sido criadas separadamente e a de que a seleção natural foi o principal agente transformador. A seleção natural, defendia Darwin, explicava como as espécies adaptam-se ao seu ambiente.

A idéia de que as espécies modificam-se ao longo do tempo não era nova em 1859. Portanto, Darwin não teve muita dificuldade em sustentá-la, dado a quantidade de evidências por ele apresentada em $A$ origem das espécies, mas a idéia de que a seleção natural era um importante mecanismo de

Artigo recebido em agosto/2008

Aprovado em fevereiro/2009 transformação evolutiva não se consolidou até a década de 1930, quando se tornou o fundamento do que veio a ser conhecido como neodarwinismo.

$A$ origem das espécies quase não fala da espécie humana. No final do último capítulo, Darwin sugeriu que a partir do estudo da evolução se esclareceria a origem do homem e sua história e, em um futuro distante, o estudo da psicologia se estabeleceria sobre novas bases (Wright, 1996). Embora em The descent of man Darwin tenha pensado sobre as origens do homem em vários sentidos que interessam às ciências sociais, conforme bem demonstrou Tort (2004) em seu esforço para elaborar uma antropologia darwiniana, foi só a partir da década de 1960 que as repercussões dos trabalhos de cientistas evolucionistas atingiram os objetos de estudos dos cientistas sociais. Darwin acertou quanto ao futuro distante. Pensar a origem do homem e sua história em termos evolucionistas e estabelecer a 
psicologia sobre novas bases, eis os ingredientes da segunda revolução darwiniana (Wright, 1996; Machalek e Martin, 2004).

Até a década de 1930, o darwinismo tinha prestígio entre alguns cientistas sociais. Combinado com a filosofia política do século XX, no que ficou conhecido como darwinismo social, ele favoreceu racistas e defensores de um capitalismo selvagem. $\mathrm{O}$ darwinismo social confundia evolução com progresso e entendia a idéia de que um indivíduo está mais adaptado como indicativo de que ele era superior. Para o darwinismo social, a evolução era um processo ininterrupto e progressivo, um programa de melhoramento. Diferentemente dos darwinistas sociais, que equivocadamente acreditavam que a biologia era tudo, ou da doutrina que o sucedeu nas ciências sociais, para quem a biologia não era nada, a segunda revolução darwiniana tem mostrado que a biologia não é tudo, mas também não pode ser desconsiderada. A biologia é importante.

Em seu livro sobre as perspectivas evolutivas para entender o comportamento social humano, Laland e Brown (2002) falam do otimismo de biólogos, antropólogos e psicólogos na aplicação de princípios evolutivos para explicar fenômenos sociais como homicídio, religião e diferença entre os sexos em termos comportamentais. Biologia, antropologia e psicologia têm sido representadas na segunda revolução darwiniana por abordagens evolucionistas como a sociobiologia, a ecologia comportamental, a antropologia darwinista e pela mais popular abordagem evolucionista do comportamento social humano do momento, a psicologia evolucionista. Pensando em termos de recombinações disciplinares, uma pergunta se coloca: e a sociologia?

Disciplina com parentesco temático, teórico e metodológico com a antropologia e psicologia, por que a sociologia não foi citada por Laland e Brown (2002)? Por que de todas as ciências sociais, a sociologia é a disciplina mais resistente a um diálogo com a biologia e com a teoria evolutiva. Quanto mais nos aproximamos das especialidades centrais da sociologia, maior a resistência. Uma análise comparativa entre a sociologia que se desenvolve nos Estados Unidos e a sociologia européia seria interessante nesse sentido, mas como não investigamos empiricamente os principais periódicos de sociologia na Europa, podemos dizer que, na análise dos dois periódicos sociológicos norte-americanos mais tradicionais, o American Journal of Sociology, (AJS) e American Sociological Review (ASR) no período entre 1960 e 1998, um dos argumentos desfavoráveis às abordagens biossociais mais recorrentes foi o questionamento sobre a pertinência da teoria evolutiva para se compreender o comportamento social humano (Ferreira, 2000).

Quando pensamos em causalidade para os seres vivos em geral, falamos de causas próximas e causas últimas. Causas próximas são as que dizem respeito ao indivíduo e seus modos de funcionamento, sejam em suas dimensões bioquímicas sejam psicológicas. Causas últimas, chamadas também de históricas ou evolutivas, são as que procuram explicar por que os indivíduos são de uma maneira e não de tantas outras possíveis. Vista a partir das especialidades estruturalmente sociológicas, áreas centrais dominadas por generalistas que zelam pela tradição da teoria sociológica, a teoria evolutiva não pode ajudar na explicação do comportamento social humano. Para sociólogos não faz sentido pensarmos os comportamentos sociais humanos em termos de causas últimas. A teoria da evolução é aceita para explicar nossa anatomia só até o pescoço. Para um sociólogo tradicional, o comportamento social humano é moldado inteiramente pelo processo de socialização, que é um processo exclusivamente sociocultural. O advento da psicologia evolucionista nos anos de 1990 ajudou a popularizar explicações do comportamento social humano que conjugam causas últimas com causas próximas, mas a sociologia continua como a última trincheira de resistência contra as explicações neodarwinistas do comportamento humano. No entanto, contrariamente ao que se apresenta, defendemos: (1) que embora a sociologia em suas especialidades mais tradicionais seja a ciência social mais resistente a engajar-se na segunda revolução darwiniana, em especialidades sociológicas periféricas o impacto da sociobiologia foi grande, com repercussões que se fazem sentir agora na agenda do campo sociológico (as divergências em torno do tipo de abordagem - se biossociologia ou sociologia evolucionista - já existiam antes mesmo do surgimento da sociobiologia); (2) que a institucionalização de uma 
sociologia evolucionista representa o triunfo da sociobiologia no campo sociológico; e (3) que tomando a sugestão de Crippen (2006), as quatro questões de Tinbergen (1963) constituem uma boa estratégia para pensarmos a sociologia evolucionista que está sendo feita e a que podemos fazer.

\section{Biossociologia ou sociologia evolucionista?}

Por volta de 1930, darwinistas e mendelianos finalmente convergiram e forjaram a Moderna Síntese ou Teoria Sintética (Huxley, 1942) sobre a proposição geral de que "todos os organismos biológicos têm evoluído como resultado da seleção natural agindo sobre variações genéticas" (Dobzansky et al., 1977), ou seja, a seleção natural representa sucesso reprodutivo diferencial, na medida em que ocorre transmissão de características favoráveis à descendência, possibilitando uma vantagem na sobrevivência daqueles indivíduos que as possuem. Após cada geração, as características favoráveis tornar-se-ão preponderantes na população, provocando pequenas mudanças evolutivas na espécie. A moderna síntese deu impulso a um número de novas disciplinas, algumas delas consolidações de desenvolvimentos antigos: biologia molecular, ecologia evolutiva, genética comportamental, primatologia e etologia. Algumas das novas abordagens evolutivas especializaram-se em etnografias animais e eventualmente em comparações entre espécies. Tal como os antropólogos, primatólogos e etólogos estudaram espécies de primatas em seus ambientes naturais, descrevendo suas organizações sociais. Por isso, eles foram atacados por defenderem similaridades em comportamentos e organizações sociais entre seres humanos e seus parentes mais próximos (Tinbergen, 1951; Goodall, 1971).

A partir da década de 1960, o alcance da moderna síntese tinha se estendido para incluir a evolução do comportamento social (Hamilton, 1964; Trivers, 1971; Williams, 1966). Em 1975, a moderna síntese tinha engendrado uma grande quantidade de dados com base em descobertas comportamentais comparativas e publicou-se um tratado que teorizava e propunha uma nova síntese (Wilson, 1975). Esta, conhecida como sociobiologia, expan- diu-se para incluir o comportamento humano (Wilson, 1981; Alexander, 1979; Lumsden e Wilson, 1981) e propôs-se a ajudar na descoberta: (1) das bases biológicas dos comportamentos sociais, inclusive o humano; (2) dos parâmetros ambientais, incluindo os culturais, que influenciam estruturas e processos genéticos.

O surgimento da sociobiologia desencadeou uma virulenta polêmica nas ciências sociais. Na psicologia e na antropologia o projeto sociobiológico foi discutido inclusive nos encontros anuais de suas associações profissionais. $\mathrm{Na}$ sociologia ficou restrito, no núcleo da disciplina, a três resenhas publicadas no American Journal of Sociology (Eckland, 1976; Mazur, 1976; Tyryakian, 1976), e breves manifestações negativas em livros de sociólogos influentes. Machalek e Martin (2004) fizeram um interessante levantamento do tratamento dado à sociobiologia em manuais de sociologia nos Estados Unidos.

$\mathrm{A}$ análise de conteúdo que fizemos do $A J S$ e ASR mostra que, desde a década de 1960, alguns sociólogos estavam atentos às descobertas comportamentais comparativas feitas por etólogos e primatólogos. Rosenberger (1966) chamou atenção de sociólogos com inclinações etológicas para as fascinantes informações fornecidas por trabalhos primatológicos que descreviam sociedades de gorilas a partir de sua dinâmica de grupo, liderança, comunicação, jogos, dominância, territorialidade, ecologia e população. Segundo ele, as analogias entre comportamentos de gorilas e seres humanos eram cuidadosas e a leitura de tais trabalhos poderia revigorar a tradição de trabalho de campo, uma tradição metodológica que tinha fracassado comparada aos surveys e aos estudos experimentais.

Eckland (1967) partiu da genética de populações para mostrar como princípios genéticos são relevantes para estudarmos a inteligência e sua relação com temas sociológicos envolvendo família, educação e mobilidade social. A resenha que Eckland (1976) fez quase uma década depois sobre o livro de Wilson (1975) mostra que ele já abordava biossocialmente fenômenos sociais há mais de uma década.

No início dos anos de 1970, um debate no ASR, veículo da Associação Americana de Sociologia, já confrontava defensores de uma biossociologia contra defensores de uma sociologia evolucionista. 
Se conceituarmos abordagens biossociais como recombinações entre especialidades das ciências sociais e biologia evolutiva (Ferreira, 2000), podemos pensá-las como produtos que têm dois pontos de partidas diferentes. Abordagens biossociais provenientes da biologia evolutiva em direção às ciências sociais e abordagens biossociais provenientes das ciências sociais em direção à biologia evolutiva. $\mathrm{O}$ trabalho de Lorenz (1979) é do primeiro tipo enquanto o de Tiger e Fox (1976) pertence ao segundo.

Os antropólogos Lionel Tiger e Robin Fox eram os dois cientistas sociais defensores de abordagens biossociais mais conhecidos no início da década de 1970. Dois de seus trabalhos publicados em parceria (Tiger e Fox, 1966, 1976) foram duramente atacados pelos cientistas sociais, conforme pode ser comprovado pelas resenhas e artigos presentes no $A S R$ e $A J S$. Em outro trabalho biossocial que enfatizava implicações sociais das diferenças sexuais em termos evolutivos, Tiger (1969) defendeu a hipótese de que os homens teriam uma propensão transmitida biologicamente e socialmente aprendida de formar laços sociais mais fortes e mais estáveis com outros homens do que com mulheres. Booth (1972) testou a hipótese de Tiger e não viu sustentação para ela. É preciso enfatizar que Alan Booth tomou a hipótese de Tiger como uma proposição que contrariava estudos sociológicos fundamentados em explicações antibiológicas em alguns casos e não-biológicas em outros, como contraponto das explicações não-biológicas do fenômeno da socialização. Houve um interessante debate teórico e metodológico nas páginas do ASR. Diferentemente de seus colegas de profissão que simplesmente condenavam ideologicamente esforços biossociais, Booth testou a hipótese de Tiger. Mas ele assim o fez porque já era um biossociólogo.

Em 1973, em um trabalho empírico que reviu os dados comparativos da literatura primatológica, Mazur sugeriu que as comparações entre espécies serviriam como base crítica para várias teorias sociológicas sobre status. Referindo-se à teoria evolutiva, ele disse: "Argumentarei contra a explicação cultural como base para padrões de status em pequenos grupos humanos estabelecidos [...]. Deixe-me estabelecer de início que rejeitar a explicação culturalista não implica que a explicação evolutiva esteja correta"
(1973, p. 513). A repercussão da literatura etológica e primatológica no campo sociológico estava passando da seção de resenhas, em que os sociólogos comentavam possíveis contribuições para a sociologia, para a seção dos artigos, em que conceitos sociológicos eram reavaliados à luz do que vinha da biologia. "Biólogos estão falando de sociologia”, já vinham chamando atenção alguns sociólogos há mais de uma década.

Em 1974, o ex-aluno e crítico de Talcott Parsons, Pierre Van Den Berhe sugeriu uma teoria biossocial para estudar a agressão humana (Van Den Berghe, 1974). Ele já havia feito uma revisão da literatura primatológica e etológica em sua perspectiva biossocial sobre idade e sexo nas sociedades humanas (Van Den Berhe, 1973). Diferentemente de Mazur (1973), Van Den Berhe defendeu uma perspectiva sociológica evolutiva para combater as explicações radicalmente ambientalistas. Ancorado na literatura etológica da época, ele defendeu que “o repertório comportamental de toda espécie é determinado, em parte, por um conjunto de predisposições biológicas que é, pelo menos em alguma extensão, específico da espécie” (1974, p. 777).

$\mathrm{O}$ artigo de Van Den Berghe provocou extensos comentários em três exemplares do ASR: outubro de 1975, fevereiro e junho de 1976. Nos dois últimos o projeto sociobiológico foi usado como fundamento sobretudo por Van Den Berghe, que utilizou o trabalho de Wilson (1975) para reforçar alguns de seus argumentos e para defender a idéia de que uma "ciência da sociobiologia é possível somente por intermédio de comparações entre espécies" (Van Den Berghe, 1976b). O sociólogo Robertson (1976) referiu-se ao termo biossociologia no sentido de uma abordagem sociológica tradicional que incorporasse a dimensão biológica sem adotar uma abordagem evolutiva para os fenômenos sociais. Mazur e Robertson (1972) já haviam sugerido o nome "biossociologia" como uma perspectiva não-biossocial, conforme o conceito que adotamos, quando escreveram Biology and social behavior. O que chama atenção na discussão do artigo de Van Den Berghe é que, com exceção de um comentador que era biólogo, todos os outros eram sociólogos que conheciam a literatura etológica e primatológica dos estudos sobre comportamento 
e organização social primata. Van Den Berghe defendeu claramente uma sociologia evolucionista nos moldes sociobiológicos, Maryanski Turner, Turner e Fix (1976b) endossaram a possibilidade de uma sociologia evolucionista, mas questionaram a maneira pela qual Van Den Berghe apreendeu a literatura sobre evolução humana, posicionando-se contrariamente a uma explicação da territorialidade e da hierarquia humanas como tendo fundamentos biológicos, enquanto Alan Mazur e Leon Robertson defenderam uma abordagem biossociológica. As divergências entre Van Den Berghe e Maryanski Turner, Turner e Fix já prenunciavam divergências em relação ao tipo de sociologia evolucionista, o que hoje presenciamos na seção "Evolução, Biologia e Sociedade" da Associação Americana de Sociologia. Em certo momento de sua réplica, Van Den Berhe afirmou: "Que evidências Turner, Turner e Fix adiantam para sustentar suas hipóteses que são tão diferentes das minhas? Considerando todos os aspectos, eu penso que o argumento deles é tão hipotético quanto o meu, como a maioria dos argumentos evolucionistas tendem a ser" (1976b, p. 557).

Com o advento da sociobiologia, Van Den Berghe passou a ser seu principal expoente na sociologia, embora outros sociólogos tenham manifestado simpatia pela nova abordagem biossocial (Eckland, 1976; Tyryakian, 1976; Ellis, 1978; Chase, 1980; Lopreato, 1984; Cohen e Machalek, 1988) para citar apenas aqueles que se manifestaram mais claramente nos dois periódicos mais tradicionais da tradição sociológica.

$\mathrm{Na}$ periferia do campo sociológico e em outras disciplinas das ciências sociais antes e após o arrefecimento do debate em torno da sociobiologia, uma comunidade crescente de cientistas sociais tem construído uma teoria social darwiniana, uma "Revolução Silenciosa" que pode ser caracterizada como uma Segunda Revolução Darwiniana (Wright, 1996). Hoje, esta revolução tem conseguido adeptos em várias das ciências comportamentais e sociais, incluindo antropologia, psicologia, neurociência cognitiva, economia, ciência política e psiquiatria e tem conseguido se estabelecer também em outras áreas das humanidades e das artes (Machalek e Martin, 2004). Na sociologia, a perspectiva biossocial de inspiração sociobiológica tem resultado em uma sociologia evolucionista cujos conceitos fundamentais e princípios teóricos derivam da biologia evolutiva contemporânea, especialmente sociobiologia e ecologia comportamental. Entre seus conceitos mais importantes está o princípio da maximização, que estabelece que organismos tendem a se comportar de uma maneira que maximiza sua aptidão inclusiva, isto é, sua total influência sobre a perpetuação de seus genes em gerações subseqüentes. A aptidão inclusiva é uma medida da participação de um indivíduo na reprodução conjunta de uma população. É, portanto, uma grandeza relativa. Ela não é alcançada apenas por meio da reprodução direta do indivíduo, mas também por intermédio da reprodução indireta, ou seja, pelo investimento do indivíduo em parentes.

Foi em 2004 que a comunidade de sociólogos aberta ao diálogo com a biologia organizou uma seção permanente na Associação Americana de Sociologia. O objetivo era criar bases institucionais dentro da sociologia para o desenvolvimento de pesquisas na interface da teoria sociológica com a biologia.

Um argumento recorrente nas comunicações dos participantes dessa seção é a importância em trazer de volta a teoria evolutiva para a sociologia. No entanto, há sérias divergências em relação à estratégia a ser adotada. Biossociologia ou sociologia evolucionista? Existe uma primeira divisão entre biossociologia e sociologia evolucionista. O nome da seção, que era "Evolução \& Sociologia" mudou, em 2008, para "Evolução, Biologia e Sociedade", o que parece contemplar esta primeira divisão. Entre os adeptos de uma sociologia evolucionista, há divergências, conforme já mencionamos, sobre o tipo de sociologia evolucionista. O casal de sociólogos (Maryanski e Turner, 1992; Turner, 2000; Maryanski, 2006) é contrário ao princípio da maximização e a uma sociologia evolucionista nos moldes sociobiológicos. As abordagens de Lopreato (1984), Lopreato e Crippen (1999), Pierre Van Den Berghe (1973, 1974, 1979), Tiger e Fox (1976) são caracterizadas como uma sociologia do instinto nos moldes elaborado por Lorenz (1979). Maryanski e Turner, por exemplo, argumentam que cientistas sociais como Van Den Berghe e Tiger e Fox vêem processos evolutivos como produtores de biogramas que, 
em termos mais amplos, dirigem e circunscrevem o padrão de organização social desenvolvido por seres humanos. Cultura e sociedade, dizem Maryanski e Turner, são mais do que meros reflexos desses biogramas. Estruturas sociais e sistemas de símbolos revelam sua própria dinâmica e propriedades emergentes, mas não são completamente divorciadas da biologia humana. Em relação à sociobiologia, Maryanski e Turner são críticos da abordagem de Williams (1966), Wilson (1975) e Dawkins (1979). Por exemplo, a idéia de que corpos humanos, sistemas de símbolos culturais e padrões de organização social são "máquinas de sobrevivência", que transmitem a unidade real de seleção natural e evolução, o gene, não é bem aceita. Segundo Maryanski e Turner, tais idéias desembocam no argumento de que estruturas sociais e cultura são recipientes elaborados ou máquinas de sobrevivência para assegurar que os genes possam maximizar sua aptidão. Padrões de parentesco e altruísmo (Hamilton, 1963, 1971) assim como o altruísmo recíproco - a idéia de que existe altruísmo entre indivíduos não aparentados geneticamente (Trivers, 1971) - "são produto da seleção natural, como ela se desenvolveu para fornecer melhores máquinas de sobrevivência para genes tentando maximizar suas aptidões" (Maryanski e Turner, 1992, p. 2). Assim, se a estrutura básica da organização humana é explicada por processos de seleção gênica, as ciências sociais devem ser um ramo da biologia, o que é irônico, segundo Maryanski e Turner, pois contraria a proposta de Augusto Comte de que a sociologia no futuro forneceria a última sistematização da biologia. O raciocínio de Maryanski e Turner aqui recorre a uma normatização epistemológica: por que a explicação tem que ser apenas sociológica? A seção que congrega a comunidade de sociólogos interessados na teoria evolutiva iniciou-se com o nome "Evolução \& Comportamento Social”. Na segunda comunicação o nome mudou para "Evolução \& Sociologia". A justificativa de Maryanski (2004) foi que o trabalho de atrair novos membros revelou que os sociólogos têm resistência a abordagens recentes, como por exemplo, a sociobiologia. As mudanças do nome da seção e suas justificativas sugerem que biossociólogos, sociólogos evolucionistas de inspiração sociobiológica e sociólogos evolucionistas anti-so- ciobiologia têm concluído que divididos eles não conseguirão transformar suas preocupações teóricas e metodológicas em uma seção na Associação Americana de Sociologia. Antes da emergência da sociobiologia, o termo evolução deixava os sociólogos arrepiados. Agora ele faz parte do nome de uma seção. O nome mudou três vezes, mas em todos eles o termo evolução permanece.

\section{Sociologia evolucionista: triunfo da sociobiologia na sociologia?}

O surgimento da sociobiologia intensificou, na periferia do campo sociológico, um movimento de crítica à natureza do conhecimento sociológico. Merton já havia chamado atenção para o caráter de filosofias totais que a grande maioria dos sociólogos dava a suas produções. Os clássicos haviam formulado orientações sociológicas gerais, cabia a seus sucessores especificar os tipos de variáveis que eram específicas de certos fenômenos sociais (Merton, 1968).

Nos anos de 1970, Gouldner (1970) diagnosticou uma crise na sociologia ocidental. Uma crise teórica e metodológica que se manifestava na fragmentação da disciplina.

A recepção hostil que a sociobiologia recebeu do mainstream da sociologia foi contrabalanceada pela simpatia de alguns sociólogos, que se manifestaram e continuam a se manifestar, intensificando críticas à sociologia e ampliando o diagnóstico de Merton e Gouldner.

Alguns periódicos dedicaram números inteiros para a discussão das implicações da proposta sociobiológica para a sociologia e para a caracterização da dificuldade da sociologia em comportar-se como um campo científico: Sociological Fórum, American Sociologist e Sociological Perspectives. No mesmo sentido foram publicados alguns livros (Van Den Berghe, 1978, 1979, Wallace 1983, Lopreato e Crippen 1999).

Em 1977, o sociólogo Lee Ellis publicou um artigo polêmico em que fez uma defesa da sociobiologia, afirmando simultaneamente que a sociologia passava por um estágio crítico de seu desenvolvimento. Havia possibilidade de a sociologia perder seu reconhecimento acadêmico se não abandonasse suas suposições tradicionais de favorecer o anti-re- 
ducionismo metodológico e explicações teleológicas para o comportamento social humano. $\mathrm{O}$ artigo provocou tamanha celeuma que influentes sociólogos se manifestaram contra o que pareceu "diagnóstico apocalíptico" para alguns. George Homans e Gehard Lenski viram exageros no diagnóstico de Ellis, mas Van Den Berghe não. Embora tenha discordado da ênfase dada por Ellis à resistência dos sociólogos ao empreendimento científico como um procedimento reducionista, Van Den Berghe (1977) concordou que o fato de o campo sociológico não se comportar como um campo científico foi decisivo para entendermos a recepção ideológica que as idéias sociobiológicas receberam na sociologia. Algumas limitações conceituais e ideológicas são mencionadas: forte viés anti-evolutivo, determinismo ambiental dogmático, visão do comportamento humano como voluntarista e de uma plasticidade quase infinita, pesada dependência de análise estatística de dados agregados e uma ênfase quase exclusiva sobre comportamento verbal e simbólico. Sobre a predição de Ellis de que a sociologia perderia seu reconhecimento como campo científico, Van Den Berghe afirmou que a sobrevivência de uma disciplina não está relacionada com sua qualidade intelectual. A sociologia do final dos anos de 1970, disse ele, não é melhor do que a sociologia de Marx, Weber e Durkheim. Algumas especialidades da antropologia, por exemplo, prosperaram no sentido de um maior reconhecimento científico. Intelectualmente, a sociologia não tem uma existência separada da antropologia. A distinção entre as duas é fruto de um acidente histórico. A sociologia constitui-se intelectualmente de uma pequena especialidade dentro da antropologia: a antropologia social das sociedades ocidentais. Se a sociobiologia tornar-se o novo paradigma dominante para o estudo científico da evolução do comportamento, então a antropologia deve logicamente tornar-se uma subespecialidade dentro da primatologia - que estuda os hominídeos, os fósseis e aqueles que ainda vivem - e a sociologia uma sub-sub especialidade dentro da antropologia (Van Den Berghe, 1977, p. 76). Parece que os receios de alguns sociólogos que acusavam a sociobiologia de imperialismo disciplinar têm lá suas razões de ser. No entanto, o próprio Van Den Berghe reconhece que esta lógica de taxo- nomia de disciplinas tem pouca chance de se institucionalizar por três razões: (1) nosso interesse narcisista em nossa própria espécie garantirá para a ciência do homem um status mais elevado do que um pequeno lugar dentro da primatologia; (2) nosso etnocentrismo tão representativo das sociedades industriais avançadas garantirá a sobrevivência redundante da sociologia próxima da antropologia, apesar da demonstrável superioridade intelectual da última sobre a primeira; (3) por uma lei parkinsoniana da expansão acadêmica, a sociobiologia pode crescer sobre ela mesma sem atrapalhar a proliferação da sociologia.

Quase vinte anos depois, Ellis (1996) retomou sua crítica, explicando o declínio da sociologia pela biofobia dos sociólogos, ou seja, a tendência a não considerar as causas biológicas do comportamento humano. Ellis apresenta quatro explicações para a biofobia: fatores semânticos, falta de treinamento em biologia, foco exclusivo sobre seres humanos e fatores morais/políticos. O diagnóstico de Lopreato e Crippen (1999) é similar. Eles reconhecem a fragilidade da sociologia como campo científico, a fragmentação e a ausência de orientações (leis), o que torna o campo sociológico refém de agendas políticas.

É difícil avaliar o impacto dessas críticas no campo sociológico, mas muita coisa tem mudado desde o aparecimento da sociobiologia. Muitos sociólogos incorporaram a sociobiologia em seus programas de curso. Um número crescente de artigos tem aparecido em periódicos tradicionais e periféricos de sociologia discutindo conceitos da nova revolução darwiniana. Com a criação da seção "Evolução, Biologia e Sociedade", dois novos periódicos declararam-se abertos à publicação de sociólogos biossociais, o Sociological Theory e o Social Forces. Manuais de sociologia têm apresentado a teoria evolutiva de uma maneira favorável, mostrando sua pertinência para a compreensão dos fenômenos sociais. Outros manuais são analisados por sua apresentação negativa da sociobiologia ou de explicações biológicas (Machalek e Martin, 2004). Sociólogos e estudantes de sociologia são convidados para participarem da seção e desenvolverem projetos de pesquisa na interface sociologia/biologia. Enfim, os sociólogos evolucionistas, sociobiologistas 
ou não, e os biossociólogos estão investigando a influência de fatores biológicos nos mais diversos comportamentos sociais humanos e há incentivo até mesmo para investigar o comportamento social de outros animais e pesquisar também a influência de variáveis sociais em fatores biológicos. Se a sociologia evolucionista e/ou a biossociologia terão sucesso não sabemos, mas pensando na agenda de pesquisas propostas, cabe uma pergunta: não era esta a sugestão da sociobiologia?

\section{Um guia para uma sociologia evolucionista}

Em um famoso ensaio da década de 1960, Tinbergen (1963) apresenta quatro questões que funcionariam como uma orientação na estruturação da análise etológica. Cada uma dessas questões tem relevância para problemas comumente investigados por sociólogos, conforme sugeriu-nos Crippen (2006). Elas serão apresentadas sequencialmente para mostrar o que tem sido feito por biossociólogos e sociólogos evolucionistas.

Questão 1 - Como o comportamento funciona? Quais são suas causas próximas? Quando estudam comportamento social humano, sociólogos raramente levam em consideração estruturas neuro-anatômicas ou processos neurofisiológicos que fundamentam sua expressão. $\mathrm{O}$ foco sociológico em termos de "causas próximas" é quase exclusivamente sobre aspectos do ambiente social e cultural que condicionam o comportamento humano. Ninguém nega, naturalmente, a significância de tal condicionamento ambiental, mas este não se manifesta em um vácuo biológico. Os indivíduos chegam equipados em seus mundos com um sistema nervoso central e endócrino formado no curso de um longo período de evolução de nossa espécie. Esta consideração é especialmente relevante à luz dos avanços que têm ocorrido na neurociência e neuro-endocrinologia e têm informado o trabalho de alguns sociólogos (Rossi, 1984; Turner, 2000; Massey, 2005). Outros têm se interessado por certos processos neurofisiológicos envolvidos na expressão do comportamento social humano. Udry (1994, 2000), por exemplo, tem explora os mecanismos hormonais que fundamentam alguns aspectos do comportamento social de gênero. No mesmo sentido, Mazur (1994, 2005) e Mazur e Booth (1998) avaliam a influência do nível de circulação de testosterona sobre padrões de comportamento de dominância em machos humanos. A consideração de variáveis neuro-anatômicas e neurofisiológicas que participam da expressão do comportamento social humano tem o potencial de enriquecer nossa compreensão da "rica estrutura do comportamento humano" (Crippen, 2006).

Questão 2 - Qual é a ontogenia do comportamento? Como ele se desenvolve ao longo do curso da história de vida do organismo? Esta questão sugere que a complexa interação entre informação genética e influências ambientais pode ser um guia produtivo para retomarmos a grande quantidade de informação descritiva que sociólogos, antropólogos e psicólogos sociais acumularam quando estudaram o comportamento social humano como um produto exclusivo da socialização e condicionamento cultural. No final década de 1960, o sociólogo Eckland (1967) propôs a integração de princípios sociológicos e genéticos para corrigirmos os excessos das teorias ambientalistas do comportamento humano. Eckland referiu-se à relevância da genética de populações para entendermos temas sociológicos como a família, educação e mobilidade social.

Questão 3 - Qual é a função do comportamento? Qual é a sua contribuição para a sobrevivência e o sucesso reprodutivo do organismo? Antropólogos orientados evolutivamente e psicólogos evolucionistas têm desenvolvidos fascinantes trabalhos investigando questões dessa natureza. Sociólogos têm potencialmente muito a ganhar se explorarem abordagens semelhantes. Por exemplo, Lopreato e Crippen (1999) ilustram como estudos do comportamento de famílias - por exemplo, escolha de parceiros, investimento parental nos filhos, padrões de casamento, divórcio e recasamento, divisão de trabalho no domicílio, e de estratificação social, as forças que fundamentam a busca por status e as condições socioculturais que governam a estrutura de desigualdade social - podem fornecer um sentido mais coerente quando olhamos em termos mais amplos os princípios teóricos que formam a estrutura da moderna ciência comportamental evolucionista. Também nesse sentido, Eckland $(1967,1968)$ foi um precursor na sociologia. 
Questão 4 - Como o comportamento evoluiu no contexto do ambiente ancestral do organismo? Esta questão, que vem sendo popularizada pela psicologia evolucionista, expande o horizonte temporal comumente empregado por sociólogos quando investigam aspectos do comportamento social. Segundo Crippen (2006), sociólogos não devem se esquecer que as inclinações comportamentais humanas têm raízes e se estendem ao longo da préhistória da nossa espécie. A ênfase de Crippen, "não devem", não é exagerada, se pensarmos no quanto da produção sociológica, como disse Van Den Berghe (1977), expressa uma visão do comportamento como voluntarista e de uma plasticidade quase infinita. $\mathrm{O}$ organismo humano em muitos aspectos cruciais tem características anatômicas, fisiológicas e traços comportamentais que emergiram e persistiram porque elas foram adaptativas no ambiente ancestral de nossa espécie, incluindo aspectos do ambiente sociocultural dos nossos forrageadores ancestrais. Evidências etnográficas, arqueológicas e históricocomparativas podem ser úteis na "reconstituição" desse ambiente sociocultural. Recentemente, alguns sociólogos tornaram-se atentos para esta possibilidade e têm utilizado tais evidências para compreender uma variedade mais ampla de temas sociológicos (Maryanski e Turner, 1992; Nolan e Lenski, 1999; Sanderson, 2001; Lenski, 2005; Massey, 2005; Turner e Maryanski, 2005).

Segundo Crippen (2006), a abordagem evolutiva tem inspirado questões incomuns para a tradição sociológica. Por exemplo, qual é a formação básica para seres humanos? A maioria dos sociólogos diria que é a família. Émile Durkheim discordaria. Ele propôs que, nos primórdios, humanos viveram em unidades baseadas em comunidades regionais. Apenas mais tarde a seleção favoreceu as divisões estáveis dentro da comunidade humana. Isto pode ajudar a explicar por que nossa necessidade por um "senso de comunidade" é tão forte e persistente nas emoções humanas encontradas em todas as sociedades humanas (Maryanski e Turner, 1992; Maryanski, 2006). Van Den Berghe (1976a, 1979) apresentou esta questão de outra forma: como surgiu a sociedade? Sem uma perspectiva evolutiva, sem uma perspectiva comparativa entre espécies não é possível respondê-la.
Alexandra Maryanski tem estudado as propensões relacionais e características estruturais de hominídeos e sociedades hominídeas. Para investigar este tema, ela emprega teoria evolutiva, análise cladística (que utiliza modelos gráficos matemáticos para explicar as relações filogenéticas entre os seres vivos, baseando-se nas comparações morfogenéticas, anatômicas etc.), teoria e ferramentas da análise de redes sociais, combinadas com registros fósseis e dados de campo sobre redes sociais de macacos vivos para fazer inferências sobre a natureza das distâncias entre os ancestrais dos seres humanos e os macacos atuais. Sua descoberta básica mostra que as populações dos últimos ancestrais comuns entre seres humanos e macacos sugerem uma falta de continuidade entre gerações e foi estruturada fundamentalmente em torno de laços sociais fracos com somente alguns poucos laços sociais fortes que podiam ser utilizados por espécies descendentes para construir estruturas de grupo coesas e estáveis. Entre os macacos vivos, os orangotangos com suas vidas quase solitárias refletem esta estrutura relacional ancestral (Maryanski, 2006). As descobertas de Maryanski sugerem que a linhagem hominídea tinha predisposições em direção a redes sociais de baixa densidade, fraca socialidade e forte individualismo. A atual pesquisa da autora busca compreender como e quando os hominídeos começaram a forjar laços sociais mais fortes.

A comunidade de sociólogos biossociais e biossociólogos têm crescido, mas ainda não é representativa no campo sociológico como um todo. A tradição da sociologia norte-americana desenvolveu laços sociais fortes com a psicologia. O desenvolvimento da psicologia evolucionista tem sido auspicioso nesse sentido, pois pode funcionar como um atrator para fazer da sociologia uma parceira em pesquisas e descobertas propiciadas pelos conceitos e instrumentos gerados pela segunda revolução darwiniana.

\section{BIBLIOGRAFIA}

ALEXANDER, Richard. (1979), Darwinism and human affairs, Washington, University of Washington Press.

BOOTH, Alan. (1972), "Sex and social participation”. American Sociological Review, 37 (1): 183-192. 
CHASE, Ivan. (1980), "Social process and hierarchy formation in small groups: a comparative perspective". American Sociological Review, 45: 905924.

COHEN, Lawrence \& MACHALEK, Richard. (1988), "A general theory of expropriative crime: an evolutionary ecological approach". American Journal of Sociology, 94: 565-501.

CRIPPEN, Thimothy. (2006), "Principles of ethology and sociological analysis". Newsletter of the ASA - Section on Evolution \& Sociology, 3 (2), fall.

DAWKINS, Richard. (1979), O gene egoista. Tradução de Geraldo Florsheim. $1^{\text {a }}$ edição. São Paulo/Belo Horizonte, Edusp/Editora Itatiaia

DOBZANSKY et al. (1977), Evolution. San Francisco, Freeman.

ECKLAND, Bruce. (1967), "Genetic and sociology (I): A reconsideration”. American Sociological Review, 32 (3): 173-195.

. (1968), "Theories of mate selection". Eugenics Quarterly, 15: 71-84.

. (1976), "Darwin rides again". American Journal of Sociology, 82 (3): 692-697.

ELLIS, Lee. (1977), "The decline and fall of sociology, 1977-2000”. American Sociologist, 12: 56-66.

. (1978), "Sociobiology and behavior by David Barash". American Journal of Sociology, 84 (1): 263-265.

. (1996), "A discipline in peril: sociology's future hinges on curing its biophobia". The American Sociologist, 27: 21-42.

FERREIRA, A. L. R. (2000), Sob o espectro de Darwin: a sociologia e as abordagens biossociais. Brasilia, tese de doutorado, Universidade de Brasília (mimeo.).

GOODALL, JANE. (1971), In the shadow of man. Boston, MA, Houghton Mifflin.

GOULDNER, A. (1970), The coming crisis of Western sociology. Nova York, Basic Books.

HAMILTON, William. (1963), "The evolution of altruistic behavior". American Naturalist, 97: 354-356. (1964), "The genetical evolution of social behavior, I and II". Journal of Theoretical Biology, 7: 1-52.

. (1971), "Geometry for selfish herd". Journal of Theoretical Biology, 31: 295-311.

HUXLEY, J. (1942), Evolution: the modern synthesis. Nova York, Harper.
LALAND, K. N \& BROWN, G. R. (2002), Sense and nonsense: evolutionary perspectives on human behaviour. Oxford/Nova York, Oxford University Press.

LENSKI, Gerhard. (2005), Ecological-evolutionary theory. Boulder/Londres, Paradigm.

LOPREATO, J. (1984), Human nature and biocultural evolution. Winchester, MA, Allen and Unwin.

LOPREATO, J \& CRIPPEN, T. (1999), Crisis in sociology: the need of Darwin. Londres, UK, Transaction.

LORENZ, K. (1979), A agressão: uma história natural do mal. Tradução de Maria Isabel Tamen. 2 ed. Lisboa, Editora Moraes.

LUMSDEN, Charles J. \& WILSON, Edward. (1981), Genes, mind and culture: the coevolutionary process. Cambridge, MA, Harvard University Press.

MACHALEK, R. \& MARTIN, M. (2004), "Sociology and the second darwinian revolution: a metatheoretical analysis". Sociological Theory, 22 (3): 455-476.

MARYANSKI, A. (2004), "Message from the chair". Newsletter of The ASA - Section on Evolution \& Sociology, fall.

. (2006), "Doing evolutionary sociology: strategies and tactics". Newsletter of ASASection on Evolution \& Sociology, fall.

MARYANSKI, A. \& TURNER, J. (1992), The social cage: human nature and evolution of society. Stanford, California, Stanford University Press.

MARYANSKI TURNER, S.; TURNER, J. \& FIX, A. (1976), "Throwing the beasts back out: a closer look at Van Den Berghe's beasts". American Sociological Review, 4: 551-555.

MASSEY, DOGLASS. (2005), Strangers in a strange land: bumans in an urbanizing world. Nova York, Norton.

MAZUR, A. (1973), "A cross-species comparison of status in small established groups". American Sociological Review, 38: 513-530.

. (1976), "On Wilson's sociobiology". American Journal of Sociology, 82 (3): 697-700. . (1994), "A neuro-hormonal model of social stratification among humans: a microsocial perspective", in L. Ellis (org.), Social stratification and socioeconomic inequality, Westport, CT, Praeger. 
. (2005), Biosociology of dominance and deference. Nova York, Rowman and Littlefield.

MAZUR, A. \& BOOTH, A. (1998), "Testosterone and dominance in men". Behavioral and Brain Sciences, 21: 353-363.

MAZUR, A. \& ROBERTSON, L. (1972), Biology and social behavior. Nova York, Free Press.

MERTON, R. (1968), Sociologia: teoria e estrutura. Tradução de Miguel Maillet. $1^{a}$ edição. São Paulo, Mestre Jou.

NOLAN, P. \& LENSKI, G. (1999), Human societies: an introduction to macrosociology. Nova York, MacGraw-Hill.

ROBERTSON, L. (1976), "A comment on biosocial theory of aggression". American Sociological Review, 41 (1): 170-172.

ROSENBERGER, L. (1966), "The mountain gorilla, by George B. Schaller”. American Journal of Sociology, 72: 315-316.

ROSSI, Alice. (1984), "Gender and parenthood". American Sociological Review, 49: 1-19.

SANDERSON, S. (2001), The evolution of buman sociality: a Darwinian conflict perspective. Nova York, Rowman and Littlefield.

TIGER, L. (1969), Men in group. Nova York, Random House.

TIGER, L. \& FOX, R. (1966), “The zoological perspective in social science". Man 1, 1:75-81. . (1976), O animal imperial. Tradução de Maria Isabel Silva Pinto Costa e Moura. Lisboa, Parceria.

TINBERGEN, N. (1951), The study of instinct. Oxford, Clarendon.

. (1963), "On the aims and methods of ethology”. Zeitschrift fur Tierpsychologie, 20: 410-433.

TORT, P. (2004), Darwin e a ciência da evolução. Tradução de Vera Lúcia dos Reis. Rio de Janeiro, Objetiva.

TRIVERS, R. (1971), “The evolution of reciprocal altruism". Quarterly Review of Biology, 46: 35-57.

TURNER, J. (2000), On the origins of human emotions: a sociological inquiry in the evolution of human affect. Stanford, CA, Stanford University Press.

TURNER, J \& MARYANSKI, A. (2005), Incest: origins of the taboo. Boulder, CO, Paradigm.

TYRYAKIAN, E. (1976), "Biosocial man, sic et non". American Journal of Sociology, 82 (3): 701-706.
UDRY, Jr. (1994), “The nature of gender". Demography, 31: 561-573.

. (2000), "Biological limits of gender construction". American Sociological Review, 65: 443458.

VAN DEN BERGHE, Pierre. (1973), Age and sex in human societies: a biosocial perspectiv. Belmont, California, Wadsworth Publishing Company. . (1974), "Bringing beasts back in: toward a biosocial theory of aggression". American Sociological Review, 39: 777-788.

. (1976a), "Reply to Hixon and Scott, and Robertson". American Sociological Review, 41: 172-173.

(1976b), "Reply to Fleising and Labovitz, and Turner, Turner and Fix", American Sociological Review, 41: 555-559.

. (1977), "Reply to Lee Ellis'The decline and fall of sociology". The American Sociologist, 12: 75-76.

. (1978), Man and society: a biosocial view. Nova York, Elsevier.

. (1979), Human family systems: an evolutionary view. Nova York, Elsevier.

WALLACE, W. (1983), Principles of scientific sociology. Nova York, Aldine Publishing Company.

WILLIANS, G. (1966), Adaptation and natural selection. Princeton, NJ, Princeton University Press.

WILSON, E. (1975), Sociobiology: the new synthesis. Cambridge, MA, Belknap/Harvard. . (1981), Da natureza bumana. São Paulo, T.A.Queiroz/Edusp.

WRIGHT, R. (1996), O animal moral. Tradução de Lia Wyler. 2 ed. Rio de Janeiro, Campus. 


\section{ABORDAGENS BIOSSOCIAIS NA SOCIOLOGIA: BIOSSOCIOLOGIA OU SOCIOLOGIA EVOLUCIONISTA?}

\section{André Luís Ribeiro Lacerda}

Palavras-chave: Biossociologia; Sociologia evolucionista; Sociobiologia; Psicologia evolucionista.

Este artigo discute a repercussão do desenvolvimento de abordagens biossociais, recombinação entre especialidades das ciências sociais e biologia evolutiva no campo sociológico. Contrariamente à idéia de que abordagens biossociais não têm espaço na sociologia, defendemos que, embora a sociologia em suas especialidades mais tradicionais e centrais seja a ciência social mais resistente a engajar-se na segunda revolução darwiniana, em especialidades periféricas o impacto da sociobiologia foi grande. Acreditamos também que a institucionalização de uma sociologia evolucionista representa o triunfo da sociobiologia no campo sociológico.

\section{BIOSOCIAL APPROACHES IN SOCIOLOGY: BIOSOCIOLOGY OR EVOLUTIONARY SOCIOLOGY?}

\section{André Luís Ribeiro Lacerda}

Keywords: Biosociology; Evolutionary sociology; Sociobiology; Evolutionary psychology.

This article discusses the impact of the development of biosocial approaches, a recombination between specialties in the field of social sciences and evolutionary biology, with the sociological field. Contrary to the idea that biosocial approaches such as sociobiology has no place within sociology, we thus defend : (1) That although sociology in its most traditional and fundamental specialties is the most adamant social science to enlist in the second Darwinian revolution, in peripheral specialties the impact of sociobiology has been considerable; (2) That the institutionalization of an evolutionary sociology represents the triumph of sociobiology in the sociological field.

\section{ASPECTS BIOSOCIAUX DANS LA SOCIOLOGIE: BIOSOCIOLOGIE OU SOCIOLOGIE ÉVOLUTIONNISTE ?}

\section{André Luís Ribeiro Lacerda}

Mots-clés: Biosociologie; Sociologie évolutionniste; Sociobiologie; Psychologie évolutionniste.

Cet article aborde la répercussion du développement des abordages biosociaux, du réarrangement entre les spécialités des sciences sociales et de la biologie évolutive dans le domaine sociologique. Contrairement à l'idée selon laquelle les abordages biosociaux n'ont pas leur espace dans la sociologie, nous soutenons, malgré le fait que la sociologie, dans ses spécialités les plus traditionnelles et centrales, est la science sociale la plus résistante à s'engager dans une seconde révolution darwinienne, que dans des spécialités périphériques, l'impact de la sociobiologie a été important. Nous croyons aussi que l'institutionnalisation d'une sociologie évolutionniste représente un triomphe de la sociobiologie dans le domaine sociologique. 